Article

\title{
Intergenerational Ties in Latinx Protestant Congregations: Sustaining Ethnicity through Organizational and Affective Connections
}

\author{
Jonathan Calvillo \\ School of Theology, Boston University, Boston, MA 02215, USA; calvillo@bu.edu
}

Received: 1 July 2019; Accepted: 23 August 2019; Published: 27 August 2019

\begin{abstract}
This paper examines the persistence of intergenerational ties within Latinx Protestant Congregations (LPCs) and the implications these ties have for the persistence of LPCs as distinctly ethnic institutions. Though studies of generational transitions within ethnic congregations tend to emphasize intergenerational discontinuity, this paper uncovers ways that Latinx Protestants maintain intergenerational ties through LPC involvement, both within and across institutional settings. Rather than focusing on the content of intergenerational transmission, such as cultural practices, ethnic material, or explicit identity labels, this paper is concerned with a more preliminary matter of ethnic identity maintenance-the persistence of channels of transmission across generations. In particular, this paper examines how LPC organizational structures sustain cross-generational links, and how later generation Latinxs express affective ties to earlier generation Latinxs. Taking a religious ecology approach, findings are based on in-depth qualitative research conducted within six LPCs, and an informal survey of eleven additional LPCs, all located in the city of Santa Ana, California, a Latinx majority city. Findings suggest that LPCs are successfully cultivating intergenerational ties among a select group of later generation Latinxs, and that later generation Latinxs who stay connected to LPCs value these ties.
\end{abstract}

Keywords: Latinx; Latino; religion; protestant; congregation; evangelical; pentecostal; ethnic; immigration; language

\section{Introduction}

This paper examines the persistence of intergenerational ties within Latinx Protestant Congregations (LPCs) and the implications these ties have for the persistence of LPCs as distinctly ethnic institutions. Intergenerational ties among co-ethnics have been noted to function as conduits of ethnic and religious identities (Baykara-Krumme and Fokkema 2019; Dollahite et al. 2019), as nodes of ethnic adaptability (Bankston and Zhou 1996; Warner 2007), and as structures of ethnic institutional reproduction (Min 2010; Min and Kim 2005). Despite the nationwide growth of LPCs (Mulder et al. 2017), one of the challenges to LPC viability remains that of intergenerational transmission, a process traditionally associated with intergenerational ties. Questions remain as to whether the growth of LPCs will extend beyond the immigrant generation to encompass subsequent generations and the extent to which later generation Latinxs will contribute to the sustainability of co-ethnic congregations. National survey data suggests that many later generation Latinxs turn to non-co-ethnic congregations; only $43 \%$ of US born Latinxs attend Latinx majority churches compared to 71\% of immigrant Latinxs (Cooperman et al. 2014). Other later generation Latinxs disaffiliate from formal religion altogether, contributing to a $9 \%$ increase in non-affiliation from the first generation (15\%) to the second $(24 \%)$ (Cooperman et al. 2014). Among unaffiliated Latinxs, 19\% were raised Protestant (Cooperman et al. 2014). Roughly a third of US born Latinx Protestants attend churches that are majority Latinx (Cooperman et al. 2014). 
This paper considers the various models of intergenerational engagement espoused by LPCs, and the distinct types of intergenerational ties articulated by later generation Latinxs affiliated with LPCs. Drawing from qualitative research conducted at multiple LPCs within a Latinx majority city, I find that LPCs employ a variety of intergenerational engagement models across congregations. At the individual level, later generation Latinx Protestants articulate a positive affect toward several types of intergenerational ties. Findings suggest that LPCs are successfully cultivating intergenerational ties among a select group of later generation Latinxs, and that later generation Latinxs who stay connected to LPCs value these ties.

Presenting a different vantage point than studies emphasizing generational discontinuities within and across ethnic institutions (Chai 1998; Kim and Kim 2012), this paper considers the ways that LPCs sustain intergenerational ties, and thus maintain the possibility for some degree of institutional ethnic persistence. Given that research points to how distancing from the immigrant generation is significant in the decline of the Latinx ethnic identity (Lopez et al. 2017), this study especially notes how LPCs sustain ties between first generation and later generation Latinxs. Rather than focusing on the content of intergenerational transmission, such as cultural practices, ethnic material, or explicit identity labels, this paper is concerned with a more preliminary matter of ethnic identity maintenance-the persistence of relational channels of transmission across generations. In particular, this paper examines how LPC organizational structures sustain cross-generational links, and how later generation Latinxs express affective ties to first generation Latinx churches and individuals. The structural ties conceptualized here emerge from organizational models that facilitate interaction across generations; the affective ties (Tan 2018) denote emotive rationales that congregants articulate about personally sustaining intergenerational contact within LPCs. Santa Ana, California provides a rich context for this study as it has been home to LPCs for generations and is currently home to an estimated seventy LPCs. Data was collected through qualitative research at Santa Ana LPCs which included interviews of congregants and church leaders as well as participant observation at church activities.

In this paper, I first review literature that conceptualizes the experience of post-1965 immigrants within congregational contexts and how immigrant congregations engage generational transitions. Subsequently, I review studies that examine how LPCs engage issues of generational differences through various congregational models. In presenting findings, I begin with a taxonomy of intergenerational engagement models employed by Santa Ana LPCs. Secondly, I examine the types of intergenerational affective ties reported by LPC congregants through in-depth interviews. Five types of affective ties emerge from the data: Familial ties, charismatic authority ties, nostalgic ties, institutional service ties, and external bridging ties. The variety of affective ties demonstrated across congregational types suggest that many LPCs do not follow a linear pathway of ethnic decline, but rather engage in a dialogical back and forth across generations and across congregations. Though some Latinxs clearly prefer church models that reflect assimilatory perspectives (Martinez 2018; Rodriguez 2011), this study focuses on ways in which Latinx congregations retain ethnicity through intergenerational engagement.

\section{Studies of Ethnic Congregational Persistence}

Numerous scholars have investigated the ways that immigrant churches remain sustainable by adapting to the changing cultural norms of subsequent generations, and/or by broadening their audiences altogether. The work of Mullins (1987) has provided much fodder for discussion on this topic. Mullins proposes a three-stage life-cycle model of immigrant church adaptation. In the first stage, immigrant churches cater to the first generation. Services are primarily conducted in the homeland language, and traditions are oriented toward the homeland. In the second stage, congregations focus on the second generation, typically offering bilingual services and appointing leaders that can address the needs of the second generation. In the third stage, churches become de-ethnicized, drawing in a multiethnic constituency and experiencing the decline of the immigrant generation. Focusing on Japanese immigrant churches in Canada, Mullins' projected institutional trajectories generally mirror the straight-line assimilation model proposed by earlier scholars of immigration (Gordon 1964). As 
with straight-line assimilation, the proposed congregational trajectory is here one of linear, gradual ethnic decline.

Current scholars have articulated various disagreements with straight-line models of congregational assimilation, with much of this criticism coming from scholars studying Asian American, especially Korean American, congregations. Alumkal takes issue with Mullins' proposition that immigrant congregations transition to focus on the second generation because of decline in immigrant members, current or potential. The Asian American congregations Alumkal studies have plenty of immigrant members to cater to, yet they still invest in offering services to the second generation and to multi-ethnic audiences. In line with research on multi-ethnic congregations (Emerson and Kim 2003), the institutional mission that churches articulate, not just immigrant decline, significantly drives their commitment to gaining and retaining a multi-ethnic audience. Dhingra (2004) notes that in some cases English-language ministries emerge from immigrant Asian congregations as extensions of the church youth group, meaning that they do not emerge from congregational decline, but from congregational support of the second generation.

Segmented views of assimilation as embraced by many scholars also cast doubt on the straight-line model of congregational assimilation. Jeung (2005), for example, notes that with the salient racialization of second-generation Asian Americans, pan-ethnic churches emerge, a configuration skipped by Mullins altogether. Moreover, as societal racialization generates a shared perception of commonality for Asian Americans, pan-ethnic congregations become more feasible as sites of community building. Second generation congregants may also choose to go the route of separate English-language congregations rather than merely hosting an English-language service within an immigrant congregation (Ebaugh and Chafetz 2000; Kim and Kim 2012), another configuration that does not quite figure into Mullins' frame. In this model, the immigrant dominant congregation remains, and an English dominant congregation hives off and becomes independent. Kim and Pyle (2004) note that such congregations often understand themselves as being culturally distinct from their immigrant parent congregations, and in some cases such churches form because of disagreements about proper cultural norms within churches (Dhingra 2004; Kim 2010). Taking it a step further, Kim argues that second generation Korean American congregations are "not mere way stations en route to assimilation," (Kim 2010, p. 12) but are actually distinct expressions of spirituality unto themselves. Nevertheless, highlighting a sense of intergenerational discontinuity, Min (2010) argues that many Korean Protestant immigrants are successful at transmitting their religious affiliations to their children, but are not successful at transmitting ethnic identities.

\section{Latinx Congregations Sustaining Ethnic Ties}

As with Asian American congregations, there are various factors that distinguish Latinx congregations from those of European immigrants of a century past in relation to the maintenance of institutionalized ethnic character (Jeung et al. 2012). For Latinxs, the historical and sustained geographic segregation of a substantial Latinx working class has significantly shaped Latinx church configurations. To this day, Latinxs experience some of the highest rates of segregation in the US (Tienda and Fuentes 2014), though some Latinxs do occupy a middle class status (Vallejo 2012). Legal status poses an obstacle to the wellbeing of many Latinxs in the US, making Latinxs "the most vulnerable of all of America's disadvantaged populations" (Massey and Pren 2012, p. 6). Sustained political rhetoric and perceptions of Latinxs as a threat (Chavez 2013) continue to mark especially darker-skinned, working class Latinxs as racialized minorities, relegated to social spaces distinct and distant from those of upper middle class whites (Bonilla-Silva 2004). Even later generation Latinxs can face backlash intended for immigrants, reinforcing a sense of racial distinction (Jimenez 2010). Such racialized boundaries mean that some Latinx congregations serve an isolated "underclass". As even Mullins' (1987) concedes, continued discrimination experienced by later generation ethnics may drive them back to immigrant congregations. Moreover, sustained structural barriers in society are one factor that bolsters the persistence of ethnically distinct communities of worship. 
Aside from externally imposed structural barriers, in-group perceptions of Latinx unity significantly influence LPCs. One important form of ethnic cohesion, pan-ethnicity, figures prominently into the configuration of LPCs. Pan-ethnicity manifests differently in Latinx churches as compared to Asian American churches in that Latinxs may be more prone to organize pan-ethnically at the immigrant generation, given shared language. In other words, pan-ethnicity may be more salient at an earlier generation for Latinxs than it is for Asian Americans. Openness to pan-ethnicity means that as new immigrants arrive in the US, Latinx churches need not limit themselves to serving only one national origin group. Certainly, congregations concentrating on one Latin American origin group do exist (Menjívar 2003; Vasquez 1999), but such congregations often change to accommodate pan-ethnic constituencies. Though many Latinxs prefer to self-identify in accordance with national origin (Taylor et al. 2012), many congregate within pan-ethnic congregations despite preferred personal labels (Mulder et al. 2017). Some leaders, in fact, as Mulder et al. (2017) point out, seek ways to promote pan-ethnic identities rather than nationally based identities, for the purpose of cultivating pan-ethnic unity across congregants. The replenishment of Latinxs in pan-ethnic fashion provides an important source of sustainability for first generation churches. Moreover, first generation churches can accommodate immigrants of various Latin American origin groups increasing the likelihood that such congregations remain "first generation" for an extended period of time even as they welcome immigrants from disparate Latin American nations.

Despite the salient effects of structural barriers and pan-ethnicity in sustaining the institutional ethnic character of LPCs, first generation LPCs still contend with the threat of decline posed by generational transitions. Some LPCs have addressed generational differences by focusing primarily on incorporating English language based classes for children and teens, some have incorporated bilingual services, and some have transitioned to separate English-language services altogether (Mulder et al. 2017; Rodriguez 2011). Though in some LPCs first generation immigrant leaders hold the most power, there are exceptions to this. The case of Templo Calvario, for example, is one in which the church is led by a later generation Mexican American pastor (Martinez 2018; Mulder et al. 2017; Rodriguez 2011); this church welcomes a substantial number of immigrants, but also engages later generation Latinxs. Templo Calvario has experimented with bilingual models of worship, and also separate language services. Nevertheless, some churches where immigrants are the majority, simply continue operating with a Spanish dominant model.

Another approach to engaging later generation Latinxs has been to form later generation ethnic dominant churches. Rodriguez divides these churches into two types: Upwardly mobile Latinx churches and "at-risk community" Latinx churches (Rodriguez 2011). In studying various cases of later generation Latinx churches, Rodriguez notes that some of these churches and church movements were founded by later generation Latinxs, such as Victory Outreach, and New Harvest Fellowship (Rodriguez 2011); moreover, not all Latinx churches have been founded by Latinx immigrants. Indicating the effects of racialization on church formation, Rodriguez notes that many later generation Latinx churches are aimed clearly at Latinxs who make up part of a societal underclass, those who have been confined to under-resourced neighborhoods. Moreover, later generation churches, for some Latinxs, do not signal social mobility, but quite the opposite. As Flores (2014) notes, churches like Victory Outreach provide Latinxs with particular tools and action strategies that draw on the street cultures that they are familiar with, and paradoxically may help them mitigate the deleterious effects of systemic oppression.

Upwardly mobile Latinxs typically have more options at their disposal in terms of where to congregate (Marti 2005). Naturally, most upwardly mobile Latinx churches are located in regions where upwardly mobile Latinxs abound. Rodriguez (2011) notes various congregations in Miami and San Antonio, for example, that have succeeded in reaching later generation Latinxs who are upwardly mobile. Upwardly mobile Latinxs also gain access to a broader range of non-Latinx dominant congregations. Marti (2005) notes the success of Mosaic church in Los Angeles in capturing a substantial number of Latinx creatives, for example. In Marti's study, Latinxs may not be the congregational majority, but they are an influential segment of the multi-ethnic Mosaic congregation. Some upwardly 
mobile, later generation Latinxs may choose to attend white dominant churches. Residential mobility and intermarriage may be among the factors that influence this choice for some Latinxs (Martinez 2018). Little is said in the literature about how upwardly mobile Latinxs might interface with predominantly working class congregations. Vallejo (2012) finds that some upwardly mobile Latinxs continue to give back to working class neighborhoods. Might upwardly mobile Latinx congregants continue to do the same within working class majority LPCs?

Based on this literature, there are several important trends that have implications for intergenerational engagement within LPCs. First of all, churches that focus on immigrants may welcome pan-ethnic congregants, an opportunity that some first generation Latinx churches have taken advantage of for decades and which replenishes first generation identities. Secondly, immigrant dominant Latinx churches attempt various models of intergenerational engagement, from Spanish only models, to bilingual worship models, to separate services models, with not one model proving to be the formula for success. Thirdly, many later generation Latinx churches have been founded independently of immigrant churches. Fourthly, many Latinx churches serve populations geographically contained by social inequality, discrimination, and issues of legal status. Fifthly, many later generation Latinx churches excel at reaching Latinxs that have experienced high levels of social dislocation. Finally, upwardly mobile Latinxs have the greatest degree of congregational options and may find options beyond the working class barriers where some of their co-ethnics reside. On the surface, this seems to indicate a highly segmented outlook across Latinx generations within LPCs. Findings indicate that at least in Santa Ana, the picture is more complex.

\section{Methods}

Data for this study was collected through structured in-depth interviews, participant observation at various LPCs in Santa Ana, California, and informal ethnographic interviews. Data collection was conducted in two waves, with each wave related to two distinct, but overlapping projects. The first wave of data was collected as part of a project that examined the role of religious affiliation in shaping the ethnic identities of Catholic and Evangelical congregants. Twenty-five adult Evangelical congregants were interviewed within this initial wave. A second wave of interviews were conducted as part of the Latino Protestant Congregations Project, a nationwide study funded by the Lilly Endowment. Interviews in the second wave of data collection adhered to an interview schedule developed by the LPC Project directors, Gerardo Marti and Mark Mulder. Twenty-seven additional adult participants took part in the second wave. Interviewees were selected via referrals from pastors and lay leaders, and then snowball sampling was employed to include additional participants. Data from both of these projects were combined for this paper as interview protocols from both projects shared similar questions about religious participation and ethnic identity. In total, fifty-two congregants from Santa Ana based LPCs took part in in-depth interviews. The interviews averaged about an hour in length and were conducted in four types of locations: At church facilities, at a neighborhood community center, at public spaces such as coffee shops, or at participants' homes. A digital audio recorder was used to record interviews, which were subsequently transcribed.

A substantial portion of the study draws from participant observation conducted at LPC related events in Santa Ana. LPC events consisted especially of worship services held at churches, but also included neighborhood-based outreach events, and city/community-based meetings of local church leaders. Participant observation at church gatherings was especially helpful for gathering data on the types of demographics of local LPCs as well as on the religious practices most typical of these congregations. In addition, through these events, I was able to interact with congregants that did not participate in in-depth interviews, and often inquired of their church-based experiences. Observations at LPCs were initially recorded through hand-written jottings, and then expanded upon through typed fieldnotes. Fieldnotes and interviews were both coded based on themes that emerged from close readings of the transcripts; the themes of this paper emerged from said readings. 
In total, I conducted extensive participant observation at six LPCs, which included in-depth interviews of multiple congregants and leaders, and multiple visits to church gatherings. In addition, through neighborhood-based events, I interacted with church pastors of eleven additional churches and was able to observe their congregational demographics during at least one church event. While these secondary cases did not involve in-depth interviews, through both informal interviews and participant observation they did provide additional data related to the models of intergenerational engagement being employed by said churches. Furthermore, the inclusion of these secondary cases revealed important points of inter-connectedness across congregations in Santa Ana. A total of seventeen LPCs provided data for this study.

The LPC congregants that were interviewed for this project reflect the broader demographics of Santa Ana's Latinx communities. Nearly 90\% of interviewees were of Mexican origin. The rest were of Salvadoran, Guatemalan, and Cuban backgrounds. Additional informal interviews were taken with people of Honduran, Ecuadorian, and Puerto Rican backgrounds. Half of the interviewees $(n=26)$, were immigrants that came to the US as adults. Twenty-six interviewees were of later generation, with eleven 1.5 generation interviewees, eleven second generation interviewees, and four of the third generation or later. About a fifth of the interviewees possessed a bachelor's degree or higher. Twenty-three interviewees identified as former Catholics, a designation almost exclusively found among first generation immigrants. Conversely, nearly all later generation interviewees had grown up in Protestant churches, or in the very least were exposed to Protestantism at a very early age. ${ }^{1}$

So too, the congregations selected for this study reflect the breadth of LPCs in Santa Ana. The initial cluster of six congregations selected for in-depth study were chosen in light of their focus on engaging residents from Santa Ana. These were congregations committed to serving their surrounding ethnic communities through their styles of worship, expressed culture, and community outreach. Correlating with their commitments, these congregations were composed significantly of local residents. Contact with additional congregations was made through visiting local church network meetings and by referrals from pastors within the initial set of churches. The traditions represented in the sample of churches, ordered from least to greatest share of congregations, included Pentecostal, Non-Pentecostal Evangelical, and Mainline congregations. Churches within the Pentecostal tradition included both denominational and independent congregations. Churches varied in their styles of community engagement, with some more committed to community engagement beyond the walls of their church and others more strictly focused on programs serving their own congregants. This distinction varied across congregational traditions. Nevertheless, all the churches tended to retain at least a minimal level of commitment to their surrounding communities through congregational membership.

\section{Context}

Santa Ana, CA, dubbed a "Latino City," (Gonzalez 2017) has been home to Latinxs since its beginnings. Many of Santa Ana's oldest Mexican barrios started as villages for citrus field laborers in the early 1900s and were characterized by high degrees of segregation (Gonzalez 1994). Latinxs would be instrumental in revitalizing the urban core of Santa Ana, helping to resuscitate a thriving business hub at the center of town. In the span of three decades, from 1960 to 1990, the Latinx population went from being $15 \%$ to $65 \%$ of the city population. Though Santa Ana is today a city of 332,725 where $78 \%$ of residents identify as Latinx, immigrant and working class Latinxs still face high degrees of social isolation (U.S. Census Bureau 2017). Nearly half of the city's population is foreign born and more than a fourth of the city's central quadrant residents are estimated to be undocumented (Marcelli et al. 2015). As residents of a city at the heart of Orange County California's thriving economy, Santa Ana's working class Latinx residents constitute a substantial segment of the Orange County labor force. Comprised of 34 cities, Orange County is home to eleven out of the one hundred wealthiest cities in

1 Pseudonyms are used for both congregants and congregations. 
the nation; three Orange County cities are in the top ten (Miller and Ramirez 2016). This contrasts with the experience of Santa Ana's majority working class population, reflected in a 2004 report from the Rockefeller Institute which declared Santa Ana to be the toughest place to live in the nation (Montiel et al. 2004). Despite these hardships, Vallejo notes that some Latinxs from Santa Ana have achieved middle class status (Vallejo 2012).

In regards to LPCs, Santa Ana presents a unique site of inquiry given its long history of LPC activity, and its current landscape of diverse LPCs. Records of Protestant outreach aimed at Santa Ana's Mexican population suggest that the California Spanish Mission Society was the first Protestant institution drawing in Latinxs in Santa Ana c. 1897 (Case 1902). Later, in 1910, the Mexican Methodist church was founded by a joint denominational effort in Santa Ana and pastored by ethnic Mexican leaders. Latinx Pentecostalism early on established a presence in the city; one notable case, Templo Calvario, one of the largest LPCs in the nation, was founded in 1925 (Leal 2009). As Latinx immigration into the city expanded, so too did LPCs. I estimate that today there are roughly seventy LPCs in the city, though an exact count is difficult given that numerous congregations share space with other congregations and meet in non-traditional church spaces. This study approaches Santa Ana not merely as a geographic location, but as a religious ecology where churches are characterized by "patterns of relations, status, and interaction among organizations" (Eiesland 2000, p. 11).

\section{Intergenerational Organizational Ties}

The abundance of congregational options for Latinxs in Santa Ana allows for congregational specialization, or the design of niche congregations (Ammerman and Farnsley 1997; Marti 2005). Such congregations can excel at meeting particular felt needs among seekers and congregants, while differentiating themselves from other local congregations. Though specialization might be understood as an element of competition, wherein congregations improve their selling points, such a view ignores other aspects of specialization that influence the local religious ecology. For example, in serving a particular niche, congregations might not equally invest in the same potential congregants. Indeed, as congregations become effective at serving distinct niches, the actual competition they are engaged in might be minimized, even if on the surface they appear to be competing for the same co-ethnics. While the focus of differences across congregations is often on stylistic distinctions, or theological disparities, the contention of this study is that generational dynamics play a significant role in the differentiation of congregations. Even as some immigrant congregations bemoan the loss of later generation congregants, such a loss relieves tension, allowing immigrant congregations to focus on immigrants. In the first section presenting findings, I categorize the distinct organizational forms that emerge among LPCs in relation to generational differentiation. Mapping out the distinct types of generational forms among Santa Ana's LPCs provides an overview of the actual options that Latinx Protestants have at their disposal.

\subsection{First Generation Churches}

First Generation Congregations cater primarily to immigrants and are composed mostly of immigrant adults and their children. Collective gatherings at such congregations are primarily conducted in Spanish and church practices often hearken to Latin America. With only a few congregational exceptions, people in positions of power are Latinxs. In Santa Ana, reflecting the demographics of the city, most first generation churches serve primarily Mexican origin populations, yet the majority if not all of the congregations I encountered were also pan-ethnic in their makeup. Central Americans make up the next Latin American region most represented, with Guatemalans and Salvadorans the two largest national-origin groups present in local LPCs. Still, there are important points of variation among first generation churches related to intergenerational engagement. 


\subsection{Monolingual First Generation Churches}

Monolingual first-generation churches cater to first-generation immigrants and conduct nearly all of their services in Spanish. One example of this type of church, El Crecimiento Espiritual, sings nearly all of its worship songs in Spanish, and its sermons are spoken completely in Spanish. Stories of migration figure into the testimony time at this independent Pentecostal church, and public prayers may involve praying for someone's woes related to their immigration status. There are a number of teens and children involved in the worship service of the church, and most of them are English dominant. On occasion, if they are asked to speak before the church, they sometimes interject English language phrases into their presentation. The lead pastors, a husband and wife team, are themselves bilingual, but rarely speak English from the front stage of the church. Immigrants at this church of one hundred or so members are mostly from Mexico, with a minority group from Central America. Six congregations in the study fit this sub-category

\subsection{Bilingual First Generation Churches}

Bilingual first-generation churches primarily cater to immigrant populations, but employ English translation as a means to engage later generation Latinxs and non-Latinxs in their midst. Iglesia Servidores, for example, offers English translation throughout the service, with an interpreter shadowing the primary preacher. The interpreters are most typically second-generation young adult volunteers who are members of the church. The music employed in worship is primarily sung in Spanish, but sometimes English versions of the songs are included in the musical repertoire. In this setting, it is usually clear that Spanish is the lead language. However, there is some variation in these congregations as the bilingual format does allow for some trading off, wherein second generation, English dominant leaders can also take the stage and Spanish speaking members do not lose their typical format as a Spanish translator is introduced. Three of the congregations studied fit within this sub-category.

\subsection{English Service Option}

Some first-generation churches offer an English service option for English dominant members. Iglesia Betel, for example, offers a completely separate English service on Sunday mornings that mirrors the earlier Spanish service. The sermon topic that is preached about in the Spanish language service is also touched on in the English language service. If there is a particular theme throughout the Spanish service, that same theme is adhered to throughout the English service. Planning for both services is conducted by leaders of both language groups working together. In the case of Iglesia Betel, attendance at English services is significantly less than attendance at Spanish services. There is not a sense, however, that English services are less invested in by the leadership (See Chai 1998), likely an extension of the fact that some of the key church leaders are themselves later generation Latinxs. Indeed, the senior pastor of the church is himself a later generation Latinx, a detail that is not uncommon among first generation churches in Santa Ana. It is important to note that a substantial number of later generation Latinxs do attend the Spanish language services at this church, often accompanying first generation family members. Two of the congregations studied fall within this sub-category.

\subsection{The 1.5 Generation Church}

As " 1.5 " is a designation denoting immigrants that came to the US as minors, this category of church can be mistakenly situated amongst first generation churches. Iglesia Otro Nivel caters to young Latinx congregants. Most services at Iglesia Otro Nivel are conducted in Spanish, including sermons and music, despite the fact that most of the church's eighty or so members are 1.5 or second generation Latinxs; the leaders themselves mirror this background. The style of worship services is modern, with much multimedia used. References made during sermons or during announcements are familiar to millenials, alluding to social media platforms, or particular clothing brands. A few immigrant parents accompany their children to the church and are able to understand most of the 
service as it is in Spanish. Pastor Antonio Arcos sees this as an opportunity to "reach the whole family". Still, there is little doubt that the institutional culture is oriented toward later generation, upwardly mobile Latinxs. The use of Spanish would seem paradoxical here, but the fact that nearly $70 \%$ of Santa Ana residents speak Spanish (U.S. Census Bureau 2017) indicates that many later generation residents are also fluent in Spanish. Moreover, the high percentage of Spanish speakers means that in numerous city sectors, Spanish use is normalized. Some later generation Latinxs prefer Spanish at church even as they are fluent in English, perhaps revealing an affinity retained from experiencing church with their parents. One church among those studied fit into this category.

\subsection{Second Generation Churches}

Second Generation churches cater to later generation Latinxs, conducting services exclusively in English. In Santa Ana, most of these churches draw from working class later generation Latinxs, particularly those that are familiar with urban Chicano culture. Some of the members of these churches are former gang members and some become engaged with these churches through rehabilitation programs or after being incarcerated. The Victory Outreach movement typifies this type of church (Flores 2014; Leon 1998), with Santa Ana having multiple Victory Outreach congregations. Rodriguez (2011) notes that a substantial number of second generation Latinx churches reach out to this particular population. Despite the structural barriers that some of these members have faced, many of them do move out of the city into surrounding communities; some move to distance themselves from neighborhood gangs. When a substantial number of such congregants move beyond the city, the congregation may seek to move out, as occurred with one such congregation during the span of my research. In at least one case, such a congregation invested in the creation of a parallel Spanish language congregation. Several of these churches are also involved in conducting outreach to Spanish dominant individuals. This suggests that some second-generation leaders are concerned with reaching their Spanish dominant co-ethnic neighbors. Though these churches are few in number in Santa Ana, they have a visible presence because they engage in street outreach initiatives and have a public presence in many of the city's most densely populated neighborhoods, particularly those neighborhoods known for gang activity. Five churches in my study fit into this category. ${ }^{2}$

\subsection{Distinct Patterns of LPC Intergenerational Engagement}

As reflected in the cases above, LPC instances of intergenerational engagement tend to differ from those of other ethnic groups along various lines. The degree of pan-ethnic immigrant replenishment in LPCs is arguably unparalleled by that of any other group. The continued presence of later generation Latinx leaders, particularly as pastors, within first generation congregations is unique, or at least unexplored in existing literature. The existence of a 1.5 generation Latinx church that engages first generation members and second-generation members presents a unique configuration, and likely one that would be difficult to find among other ethnic groups. Finally, the launching of a Spanish language congregation by a second-generation congregation is a configuration that is distinct from the models presented in most studies of generational transitions. This survey of a cluster of LPCs in Santa Ana, then, suggests that LPCs engage in forms of intergenerational engagement distinct from that of other ethnoreligious groups.

\section{Intergenerational Affective Ties}

Though the church categories presented above may seem like a sequence of generational progression wherein Latinxs eventually move on to predominantly white churches, observation of and conversation with later generation Latinxs reflect patterns that belie a straight-line assimilatory

2 I estimate that these churches are over-represented in this study. 
scheme. Five general trends of affective ties confound linear trajectories of generational membership: Familial ties, ties to charismatic authority figures, ties of institutional service, ties of nostalgic return, and ties of external bridging. I refer to these as affective ties because congregants describe them along emotive lines. Rather than pushing later generation Latinxs away from immigrant Latinxs, these trends among Latinx churches serve to sustain intergenerational ties for at least some Latinxs. Some of the examples provided demonstrate how later generation Latinxs maintain ties to first generation congregations. Other cases demonstrate how later generation congregations sustain ties to first generation Latinxs. Still other cases demonstrate how various types of Latinx churches facilitate the maintenance of ties to Latinx and Latin American communities.

\subsection{Familial Ties}

For many later generation Latinxs, familial ties are the primary motivator for staying connected to first generation congregations. For example, Jessica doubles up on church services every week, and one of the churches she attends is the first-generation church her mother is a member of (see Kurien 2017 for similar cases). Jessica herself is a member of Iglesia Betel, where she attends weekly, but on most Sundays she also visits her mother's church. Once a member of her mother's church, a Latinx mainline congregation, Jessica was drawn to a more charismatic style of worship. She now considers herself to be Pentecostal because she believes in the "gifts of the Spirit". Though she is fluent in English, is a white-collar professional in her early thirties, and holds a master's degree, she prefers to worship in a Spanish speaking congregation with mostly working-class co-ethnics. Many of her friends are second generation Latinxs, though she is of the 1.5 generation, having come to the US as a child. Jessica explains that she returns to her mother's church because her mother has expressed that she enjoys seeing her there. She sees her mother numerous times a week, but "there is something special" about joining her mother for Sunday worship, Jessica expresses.

Jacob is a second-generation college student that enjoys his role playing on the worship music team at Iglesia Betel. After services, he comes down from the stage and can be seen commiserating with his parents, particularly his father, who is a deacon at the church. Jacob expresses that he enjoys playing worship music in Spanish, but he also explains that beyond his public service in the church, much of his religious identity comes from his home life. He indicates that at home, he and his family "sit together and have moments of teaching and prayer," even as he is in his twenties. His continued involvement in a first-generation church is in many ways an extension of his familial practices at home-practices that Jacob takes pride in. Jacob admits, "For me, I'm used to worshipping with my family".

Cases like those of Jessica and Jacob point to the power of familial ties in retaining acculturated Latinxs within first generation Latinx churches. For Jessica and Javier, there is value in worshipping together with family members. Both of these individuals consume English speaking media such as music and film that is primarily oriented to the US not toward their families' nations of origin. Still, the church experience resonates with them because of the presence of their family members, among other things. Neither Jessica nor Jacob communicate a sense of obligation in having to attend church alongside of their parents. To the contrary, this seems to be a bonus for both of them. Though, Jessica's case shows that her family's church is not her primary church, she has remained connected to a church that is generationally congruent with that of her mother.

\subsection{Charismatic Authority}

For some later generation Latinxs, a sense of charismatic authority keeps them connected to first generation churches. Charismatic authority is typically linked to congregational leadership. James, a second generation Latinx, is simultaneously a member of an LPC and an African American congregation. He explains his ties to an LPC in the following manner: "I'm connected at the [African American congregation], but I always go back to my church. That's where I have my spiritual covering". James has a positive experience at the African American church he attends, explaining that he enjoys 
the sermons and the worship music there, but he believes that Iglesia Ebenezer, his Latinx church, offers him a type of spiritual support that he does not receive elsewhere. James and several others employ the term covertura, or covering, to indicate a type of spiritual association that one has with an authority figure or institution. James explains further by describing, "when I'm going through an important moment of decision, or need counsel, I do go and speak to my pastor there at Iglesia Ebenezer". Iglesia Ebenezer is an independent Pentecostal church, and James' views reflect a charismatic theology compatible with that of the church.

Ariana, a second-generation Latina, was faced with a decision about what church to attend. An opportunity to lead a ministry at a local multi-ethnic congregation where she had friends in leadership presented itself. Rather than merely making the decision on her own, Ariana consulted with the pastor of her mostly first-generation congregation. The pastor gave her his blessing to go ahead and shift her membership to the other church. Ariana is now involved in overseeing a ministry at a multi-ethnic church in the city, but she maintains a positive relationship to her former first-generation church, having an open door to participate there whenever she wants. Though in Ariana's case she left a first-generation church, she explains that she "maintain[s] contact with several of the pastors there, and I have a lot of respect for them".

Maritza, a 1.5 generation college educated Latina, could easily attend a non-Latinx church but she prefers to worship in Spanish. She and her husband, who is third-generation Mexican-American, worship at Iglesia Betel's Spanish service. Maritza opines that worship in Spanish is "spiritually deeper," whereas worship in English feels more "shallow". She talks about a spiritual anointing that is present in the Spanish service and that she believes that immigrants have a stronger sense of spiritual authority because of the many hardships they have endured. While Maritza does not point to a singular leader that epitomizes spiritual authority, she does articulate a sense of spiritual authority that permeates the first-generation congregants she worships alongside of. This link to first generation Latinxs carries over to her husband, as she notes that her husband has improved his Spanish through being married to her and through attending a Spanish language service, exemplifying what Martinez describes at the "eternal second generation" (Martinez 2018, p. 41).

Notions of spiritual authority are particularly pervasive within Pentecostal sectors of later generation Latinxs. Some use terms such as "madre/padre espiritual" [spiritual mother/father] to denote ties they have to a leader that has mentored them along in their spiritual path. Similar to familial ties, these ties of perceived spiritual authority help some later generation Latinxs to stay connected to first generation churches. Opportunities to seek the blessing of one's Latinx pastor, or to receive prayer during an important life decision, are of utmost importance to some Latinxs. Javier, a second-generation college educated professional summed this experience up in the following way: "In this church I've learned about the importance of spiritual authority and how I need to learn from my leaders. Ever since Pastor talked about that it hit me in the heart. I knew I needed to follow the spiritual leadership of the church". This view of spiritual authority, then, sustains the affect that some later generation Latinxs feel toward first-generation leaders.

\subsection{Nostalgic Return}

Some later generation Latinxs articulate a nostalgic connection that they have to first-generation churches made salient when they first encounter or re-encounter a first-generation church. Raymond, a working class, second-generation Latinx, wanted to try out a new church and began to attend a multi-ethnic church in the area. He enjoyed the new friends he was making and became involved in some of the church ministries. However, after about a year, he began to periodically go back to his former church, a predominantly first-generation congregation. Initially, he noticed how in his word, the preaching content and style of his original church was "anointed". As the novelty of the multi-ethnic church wore off for Raymond, he completely returned to his first generation Latinx church. He was comforted when one of the leaders there told him, "you're home now". Raymond relayed the words of the pastor to me with conviction, explaining, "I know that's my church. That's where I 
feel at home" Raymond adds that in settling back into his original church, he now feels "spiritually fed". There is a particular aesthetic that Raymond grew accustomed to from his first-generation church that he was not experiencing in the multi-ethnic church he attended. Raymond has continued in the first-generation church for several years now.

Javier, a college educated professional, had stopped going to any church for over ten years. Though he is second generation, when he decided to return to church, the natural place to go was the first-generation church he had formerly attended. Javier recalled that his parents had had a life-changing experience at the church and decided, "I have to go back". Upon his return, he was pleasantly surprised by what he experienced, and described that he "felt great to be there". Javier could have easily looked to attend a white majority church, or an English-speaking church, but he felt a tie to the church he was familiar with. Now married, Javier and his partner Lucia join his parents for Sunday worship services weekly. Javier expresses that this is the "only church that I've really belonged to. This is my church!" Some later generation Latinxs communicate a type of familiarity that comes from returning to first-generation churches.

For some nostalgic returners, their experience of return is primarily characterized by a sense of returning to one's culture. This is the experience of Dalia, a third generation Latina in her late 70's, who had been a part of various Evangelical churches through her adult life. The most recent church Dalia had been a member of was a predominantly white church on the edge of the city, but she had also attended several second-generation churches. One of her step-daughters and her husband are pastors of a Second Generation Victory Outreach church in the Los Angeles area, a church she had previously visited. When she was invited to attend El Crecimiento Espiritual, a first-generation church, the church left a positive impression on her. She explains, "this was the first church [that I attended] that in reality was Mexican and that everything was in Spanish". She says that she feels at home in the culture of the church. It is new to her, but it also feels familiar. A cultural element that Dalia appreciates about the church is that "people here look after me. They're always checking up on me and they treat me like I'm part of their family. It's part of the culture here". Dalia attributes the welcome she has received to the first-generation culture she is surrounded by. For these members, then, nostalgic returns are connected to a sense of familiarity in religious experience, or in culture.

\subsection{Institutional Service}

Leadership roles in Santa Ana's LPCs provide an important type of opportunity for cross generational interaction. While existing life-cycle models tend to assume that immigrant leaders oversee immigrant congregants, and that later generation leaders oversee later generation co-ethnics, LPCs in Santa Ana often deviate from this pattern. In particular, the involvement of later generation pastors in the lives of first-generation congregations breaks with the assumed pattern. In the case of Casa de Alabanza, for example, a second-generation Mexican American pastor tends to a congregation comprised heavily of immigrants from Central America. Most church services are conducted in Spanish by this second-generation pastor, and the pastor works with many of his congregants from Central America in allowing them input on worship service practices. At Iglesia Betel, one of the pastors on staff is not fluent in Spanish, and yet through a translator, is able to preach to first-generation congregants. Several congregations reflect these generational cross-overs.

Among the first-generation churches I observed several have later generation members in highly visible positions of secondary leadership. Roles involving music are among the more prevalent of these positions. Though some positions related to music ministries are less visible, particularly when they involve doing work behind the scenes, in many cases second-generation congregants have primary roles as worship leaders; the voices of these leaders are prominently and consistently heard by the congregation. Positions of youth leadership also often fall on second generation leaders. As Kim (2011) illustrates, sometimes youth ministry positions given to second-generation leaders can be fraught with tension as some ideas proposed by second-generation leaders may not devalued by first-generation leaders. Nevertheless, I observed several second-generation youth leaders climb the ranks within 
first-generation churches. In one case, a second-generation youth leader was promoted to the role of associate pastor. The visibility and influence of these positions has potential for making a bilateral impact, as congregants are exposed to the work of second-generation leaders and second-generation leaders maintain ties to first-generation congregants.

The presence of later generation leaders within first generation congregations is especially important in light of the authority that is typically imbued upon leaders within the context, especially upon pastoral leaders. Pastors serve as examples to their congregants, and many congregants internalize the values that are expressed by their pastors. At Iglesia Betel, and Casa de Alabanza, for example, the pastors are seen as confidants by many congregants. This is largely a symbolic understanding, as the congregations are numerous enough so that not all members are able to have direct contact with the pastors. Still, the lives of these pastors are seen as lives to emulate. In focusing on the religious practices and the lifestyle choices of pastors, congregants are able to retain important archetypes of what people in their faith and of their ethnicity are "supposed" to look like in the US. Later generation pastors, in this regard, provide not only images of spiritual vibrancy, but also of socio-cultural incorporation. Whereas some research focuses on the authenticity policing of later generation Latinxs by immigrants when immigrants are the majority (Jimenez 2010), these church settings demonstrate the influence of later generation ethnics on an immigrant majority. Certainly power dynamics matter, but churches are voluntary institutions and the first generation faithful have many other congregational options in the area that do not include later generation pastors at the head of the organization. Many chose to be at congregations where later generation Latinxs are represented in the leadership. An added caveat here is that later generation Latinxs might feel more welcome at first-generation LPCs where second-generation leaders are in positions of leadership.

\subsection{External Bridging}

Collaboration across congregations at times creates opportunities for intergenerational engagement when congregations serving distinct demographics work together. While there is a structural element to these types of collaborations, there is also an affective one in that individuals involved often express a recognition of value in these types of efforts. Moreover, some see the value in this work, and some express feeling valued in participating in this work. For example, Roberto is an immigrant that oversees the youth ministry at Casa de Alabanza and helps to facilitate intergenerational ties through congregational collaborations. His church is a first-generation congregation that conducts all services in Spanish, and periodically hosts youth services where guest preachers speak directly to the youth group. One of the activities that Roberto most excitedly talks about, however, does not take place at his congregation. He explains, "we host youth rallies at my daughter's church. My daughter is part of a church in [a neighboring city], and when they do youth rallies there, our youth group is invited". As he shows me some of the promotional material from his daughter's church, revealing modern graphic design, it is clear that the church is geared toward an upwardly mobile Latinx population. The suburban location of his daughter's church also differs from the location of Casa de Alabanza, which is in a working class, semi-industrial part of Santa Ana. Still, these congregations are connected by ethnic and familial ties across generations.

A major initiative in Santa Ana during the span of my research focused on uplifting local neighborhoods deemed to be "at-risk" through a blend of social opportunities and a Christian message. The initiative, called Love Santa Ana, was a collaboration between a number of churches from a variety of backgrounds. The efforts would unite congregations in putting on fairs within local working-class neighborhoods. Several of the churches participating were Latinx churches, and several others included majority Asian American and majority white churches. For several of the Latinx majority churches, serving in these events offered the opportunity to engage in service to local majority immigrant neighborhoods. For one of the participating congregations, though it was a first-generation church, many of those serving were second-generation members. These were members that readily communicated and collaborated with non-Latinx church volunteers. Moreover, these types of events 
offered opportunities for second-generation members who were members of first-generation churches to activate their social and cultural capital in collaborating beyond the bounds of their congregation.

In similar fashion to the work being done in local neighborhoods, some second-generation members of first-generation churches collaborated with white majority churches in conducting mission trips to Latin America, especially Mexico. Iglesia Servidores, for example, who had affiliation with a white majority church in the area, typically partnered with that church in conducting building projects and in doing church work in Mexico. Second generation members occupied a unique role in their first-generation church as they could readily travel to Mexico, serve as translators, and work alongside their white counterparts in the projects at hand. Legal status, a precarious aspect for many co-ethnics in these churches, was not an issue for second-generation congregants. Griselda, a college educated second-generation Latina, shared with the congregation after returning from one mission trip that she "had never experienced something like this before. The way that we served alongside the people from the other church, and the way we were able to accomplish their building project is something I'll remember for a long time". The involvement of first-generation churches in these collaborative initiatives provides opportunities for later generation Latinxs to not only serve, but to also function as important connectors between their first-generation co-congregants, non-Latinx collaborators from other churches, and members of the communities being served.

\section{Discussion}

The patterns of intergenerational engagement demonstrated by Santa Ana LPCs diverge from linear trajectories of institutional adaptation characterized by intergenerational discontinuity. Rather than merely disengaging from contact with first-generation individuals, many later generation LPC congregants articulate ways in which they remain connected to first-generation congregations and individuals. Based on both the inventory of organizational structures and on congregants' descriptions of intergenerational ties, several trends diverge from straight-line assimilation trajectories. First of all, some first-generation LPCs employ later generation leadership, even at the senior pastor level. Secondly, some later generation Latinxs choose to attend Spanish language worship services regularly, even in cases where an English option is easily accessible. Thirdly, some later generation Latinxs worship in bilingual services alongside of first-generation congregants. Fourthly, some later generation LPCs engage in service and outreach to first generation Latinxs demonstrating intentional concern for their first-generation co-ethnics. Finally, some later generation Latinxs participate in more than one congregation as a way to sustain ties to first generation Latinxs (Kurien 2017). It is notable that the progression with which LPCs and LPC members adapt models of intergenerational engagement in some cases move in directions contrary to straight-line assimilation trajectories, as is the case when later generation LPCs seek to incorporate first generation members. This persistence of intergenerational ties is not contingent upon only one type of congregational model but is rather effected through a variety of models.

For those later generation Latinxs that remain engaged in LPCs, the affect toward intergenerational ties seems to be a valued aspect of their religious experience. Findings suggest that perhaps intergenerational ties are one of the primary reasons that some later generational Latinxs remain connected to LPCs, even when other options are available. While some specifically articulate their intergenerational ties as familial ties, for others these ties are generalized to a broader connection with first generation Latinxs. That is, intergenerational ties, for some, are more than just staying in touch with family through church. Some later generational Latinxs draw value from the cultural experience they gain via first generation contacts. One congregant even understands the first-generation worship experience as having more spiritual depth than worship in other contexts. To be fair, later generation Latinxs that remain in LPCs are a subpopulation of the broader Latinx Protestant population. Still, it is notable that the majority of later generation Latinxs interviewed for this study grew up in Protestant households and had parents that had been Protestants for an extensive period of time. The valuing of intergenerational ties in relation to LPC affiliation perhaps correlates with an experience of a positive 
upbringing within LPCs. If it is the case that those who value intergenerational connections are primarily individuals who have an extensive history within LPCs, it is also highly probable that such congregants have stronger and more varied affective ties to LPCs. Such individuals would likely report a multiplicity of affective connections within LPCs, making it more difficult to completely divest themselves from an LPC experience.

The role of the religious ecology presents an additional dimension to consider in analysis of these findings. Many of the types of affective intergenerational ties that congregants report are tied to their experiences within the local religious ecology broadly. That is, congregants come to articulate their sense of affect within a context wherein a plethora of options exist. Affect within a particular congregational setting is in some cases articulated in contrast to experiences within other congregational settings. Some people that articulate a sense of nostalgic return, for example, experienced other congregations in the region. Some remain tethered to particular LPCs even as they participate in multiple congregations at once. Some serve as bridges across congregations in the midst of organizational collaborations taking place within the broader religious ecology. The experience of religious institutions within the religious ecology continues to be an experience of options, even if congregants are faithful to only one option. The awareness of options in the broader religious ecology, then, factors into the articulation of the congregational choices made (Stark and Finke 2000). As such, broadening the discussion to the level of the local religious ecology allows for relationships across institutions to also be factored in. Intergenerational ties that reside in spaces between or beyond institutions need not be ignored. Even when individuals engage in instances of apparent distancing from ethnic institutions, the broader religious ecology provides opportunities for personal affective ties to be legitimized and enacted.

\section{Conclusions}

Examining intergenerational ties within LPCs opens a less-trodden route to reflect upon ethnic congregational persistence among LPCs. While the existence of intergenerational ties do not guarantee that LPCs will persist as distinctly ethnic institutions, they do suggest the possibility of persistence. There are various ways that the intergenerational ties highlighted in the study may contribute to the persistence of ethnically distinct institutions. Intergenerational ties contribute to some degree of ethnic social closure, a structural aspect of ethnic persistence (Wimmer 2013). As co-ethnics remain connected through ethnic religious communities, they sustain distinctly ethnic networks which individuals come to rely on as sources of social support. As channels of ethnic and religious transmission, these ties may also help to ensure that LPCs maintain some level of cultural distinction within broader US society; an open channel of intergenerational communication may provide narratives counter to the discourses prevalent in broader society. Likewise, if this transmission is reproduced across time, the possibility for historical stability is heightened, another important aspect of ethnic identity persistence (Wimmer 2013). Though Catholicism has traditionally been associated with more salient Latinx identities than Protestantism (Calvillo and Bailey 2015), the maintenance of intergenerational ties within LPCs suggests that Latinx Protestantism may persist as a distinct alternative ethnoreligious tradition among US Latinxs. Moreover, rather than functioning as simply a stepping-stone toward affiliation within predominantly white institutions, or towards disaffiliation from formal religion altogether, some later generation Latinx Protestants continue to draw ethnoreligious material from LPCs through creative intergenerational engagement.

In conclusion, there are important limitations to this study which merit attention. The study is limited by its focus on Latinxs that remain connected —or at least remain close-to LPCs. More research is needed to understand the experiences of those that have left LPCs. How might former members of LPCs, who now identify as unaffiliated, articulate their relationship to LPCs? More specifically, how might such individuals negotiate intergenerational ties that were previously mediated by their membership in LPCs? Similar questions might be examined more systematically among later generation Latinxs who are Protestant but are members of non-co-ethnic congregations. Do such individuals mirror Min's (2010) research on Korean Americans who retain their faith but embody an 
attenuated ethnic identity? Finally, as religious conversion is not a central component of this study, how might religious change, resulting in differences across ethnic networks, influence the maintenance of intergenerational ties? The maintenance of intergenerational ties remains an important avenue of exploration for scholars interested in how religious affiliations among US Latinxs shape Latinx ethnic identities.

Funding: Funding for data collection was provided by the Latino Protestant Congregations Project through a grant from the Lilly Endowment.

Conflicts of Interest: The author declares no conflict of interest.

\section{References}

Ammerman, Nancy Tatom, and Arthur Emery Farnsley. 1997. Congregation \& Community. New Brunswick: Rutgers University Press.

Bankston, Carl L., and Min Zhou. 1996. The Ethnic Church, Ethnic Identifcation, and the Social Adjustment of Vietnamese Adolescents. Review of Religious Research 38: 18-37.

Baykara-Krumme, Helen, and Tineke Fokkema. 2019. The Impact of Migration on Intergenerational Solidarity Types. Journal of Ethnic and Migration Studies 45: 1707-27. [CrossRef]

Bonilla-Silva, Eduardo. 2004. From Bi-Racial to Tri-Racial: Towards a New System of Racial Stratification in the USA. Ethnic and Racial Studies 27: 931-50. [CrossRef]

Calvillo, Jonathan E., and Stanley R. Bailey. 2015. Latino Religious Affiliation and Ethnic Identity. Journal for the Scientific Study of Religion 54: 57-78. [CrossRef]

Case, Alden. 1902. The Pacific. Edited by William W. Ferrier and J. W. Douglas.

Chai, Karen. 1998. Competing for the Second Generation: English-Language Ministry at a Korean Protestant Church. In Gatherings in Diaspora: Religious Communities and the New Immigration. Edited by R. Stephen Warner and Judith G. Wittner. Philadelphia: Temple University Press, pp. 295-331.

Chavez, Leo. 2013. The Latino Threat: Constructing Immigrants, Citizens, and the Nation. Stanford: Stanford University Press.

Cooperman, Alan, Mark Hugo Lopez, Cary Funk, Jessica Hamar Martínez, and Katherine Ritchey. 2014. The Shifting Religious Identity of Latinos in the United States. Washington: Pew Research Center.

Dhingra, Pawan. 2004. 'We're Not a Korean American Church Any More': Dilemmas in Constructing a Multi-Racial Church Identity. Social Compass 51: 367-79. [CrossRef]

Dollahite, David C., Loren D. Marks, Kate P. Babcock, Betsy H. Barrow, and Andrew H. Rose. 2019. Beyond Religious Rigidities: Religious Firmness and Religious Flexibility as Complementary Loyalties in Faith Transmission. Religions 10: 111. [CrossRef]

Ebaugh, Helen Rose, and Janet Saltzman Chafetz. 2000. Dilemmas of Language in Immigrant Congregations: The Tie That Binds or the Tower of Babel? Review of Religious Research 41: 432-52. [CrossRef]

Eiesland, Nancy L. 2000. A Particular Place: Urban Restructuring and Religious Ecology in a Southern Exurb. New Brunswick: Rutgers University Press.

Emerson, Michael O., and Karen Chai Kim. 2003. Multiracial Congregations: An Analysis of Their Development and a Typology. Journal for the Scientific Study of Religion 42: 217-27. [CrossRef]

Flores, Edward. 2014. God's Gangs: Barrio Ministry, Masculinity, and Gang Recovery. New York: NYU Press.

Gonzalez, Gilbert G. 1994. Labor and Community: Mexican Citrus Worker Villages in a Southern California County, 1900-1950. Urbana: University of Illinois Press.

Gonzalez, Erualdo R. 2017. Latino City: Urban Planning, Politics, and the Grassroots. Abingdon: Taylor \& Francis. Gordon, Milton M. 1964. Assimilation in American Life. New York: Oxford University Press.

Jeung, Russell. 2005. Faithful Generations: Race and New Asian American Churches. New Brunswick: Rutgers University Press.

Jeung, Russell, Carolyn Chen, and Jerry Z. Park. 2012. Introduction: Religious, Racial, and Ethnic Identities of the New Second Generation. In Sustaining Faith Traditions: Race, Ethnicity, and Religion among Latino and Asian American Second Generation. Edited by Carolyn Chen and Russell Jeung. New York: New York University Press, pp. 1-24. 
Jimenez, Tomas. 2010. Replenished Ethnicity: Mexican Americans, Immigration, and Identity. Berkeley: University of California Press.

Kim, Sharon. 2010. A Faith of Our Own: Second-Generation Spirituality in Korean American Churches. New Brunswick: Rutgers University Press.

Kim, Rebecca Y. 2011. Religion and Ethnicity: Theoretical Connections. Religions 2: 312-29. [CrossRef]

Kim, Sharon, and Rebecca Y. Kim. 2012. Second-Generation Korean American Christians' Communities: Congregational Hybridity. In Sustaining Faith Traditions: Race, Ethnicity, and Religion among the Latino and Asian American Second Generation. Edited by Carolyn Chen and Russell Jeung. New York: New York University Press, pp. 176-93.

Kim, Henry H., and Ralph E. Pyle. 2004. An Exception to the Exception: Second-Generation Korean American Church Participation. Social Compass 51: 321-33. [CrossRef]

Kurien, Prema A. 2017. Ethnic Church Meets Megachurch: Indian American Christianity in Motion. New York: NYU Press.

Leal, Fermin. 2009. Templo Calvario Debuts New \$11 Million Sanctuary. Orange County Register, July 5.

Leon, Luis. 1998. Born Again in East LA: The Congregation as Border Space. In Gatherings in Diaspora: Religious Communities and the New Immigration. Edited by R. Stephen Warner and Judith G. Wittner. Philadelphia: Temple University Press, pp. 163-96.

Lopez, Mark Hugo, Ana Gonzalez-Barrera, and Gustavo López. 2017. Latino Identity Declines Across Generations as Immigrant Ties Weaken Pew Research Center. Washington: Pew Research Center.

Marcelli, Enrico A., Manuel Pastor, and Steven P. Wallace. 2015. Toward a Healthy California. Los Angeles: University of Southern California, Center for the Study of Immigrant Integration.

Marti, Gerardo. 2005. A Mosaic of Believers: Diversity and Innovation in a Multiethnic Church. Bloomington: Indiana University Press.

Martinez, Juan Francisco. 2018. The Story of Latino Protestants in the United States. Grand Rapids: William B. Eerdmans Publishing.

Massey, Douglas S., and Karen A. Pren. 2012. Origins of the New Latino Underclass. Race and Social Problems 4: 5-17. [CrossRef] [PubMed]

Menjívar, Cecilia. 2003. Religion and Immigration in Comparative Perspective: Catholic and Evangelical Salvadorans in San Francisco, Washington, D.C., and Phoenix. Sociology of Religion 64: 21-45. [CrossRef]

Miller, Courtney, and Veronica Ramirez. 2016. 'Wealthiest' Cities: How Income, Home Values and Credit Limits Stack up Around the US. NerdWallet. Available online: https://www.nerdwallet.com/blog/finance/high-rollercities-wealth-credit-highest/ (accessed on 26 June 2019).

Min, Pyong Gap. 2010. Preserving Ethnicity through Religion in America: Korean Protestants and Indian Hindus Across Generations. New York: NYU Press.

Min, Pyong Gap, and Dae Young Kim. 2005. “Intergenerational Transmission of Religion and Culture: Korean Protestants in the U.S.". Sociology of Religion 66: 263-82. [CrossRef]

Montiel, Lisa M., Richard P. Nathan, and David J. Wright. 2004. An Update on Urban Hardship. Albany: Rockefeller Institute of Government, State University of New York.

Mulder, Mark T., Aida I. Ramos, and Gerardo Martí. 2017. Latino Protestants in America: Growing and Diverse. Lanham: Rowman \& Littlefield.

Mullins, Mark. 1987. The Life-Cycle of Ethnic Churches in Sociological Perspective. Japanese Journal of Religious Studies 14: 321-34. [CrossRef]

Rodriguez, Daniel A. 2011. A Future for the Latino Church: Models for Multilingual, Multigenerational Hispanic Congregations. Westmont: InterVarsity Press.

Stark, Rodney, and Roger Finke. 2000. Acts of Faith: Explaining the Human Side of Religion. Berkeley: University of California Press.

Tan, Jo-Pei. 2018. Do Grandparents Matter? Intergenerational Relationships between the Closest Grandparents and Malaysian Adolescents. Contemporary Social Science 13: 246-60. [CrossRef]

Taylor, Paul, Mark Hugo Lopez, Jessica Hamar Martínez, and Gabriel Velasco. 2012. When Labels Don't Fit: Hispanics and Their Views of Identity. Washington: Pew Research Center.

Tienda, Marta, and Norma Fuentes. 2014. Hispanics in Metropolitan America: New Realities and Old Debates. Annual Review of Sociology 40: 499-520. [CrossRef] 
U.S. Census Bureau. 2017. American FactFinder-Results. Available online: https://factfinder.census.gov/faces/ tableservices/jsf/pages/productview.xhtml?src=CF (accessed on 25 June 2019).

Vallejo, Jody. 2012. Barrios to Burbs: The Making of the Mexican American Middle Class. Palo Alto: Stanford University Press.

Vasquez, Manuel A. 1999. Pentecostalism, Collective Identity, and Transnationalism among Salvadorans and Peruvians in the U.S. Journal of the American Academy of Religion 67: 617-36. [CrossRef]

Warner, R. Stephen. 2007. The Role of Religion in the Process of Segmented Assimilation. The ANNALS of the American Academy of Political and Social Science 612: 100-15. [CrossRef]

Wimmer, Andreas. 2013. Ethnic Boundary Making: Institutions, Power, Networks. New York: Oxford University Press.

(C) 2019 by the author. Licensee MDPI, Basel, Switzerland. This article is an open access article distributed under the terms and conditions of the Creative Commons Attribution (CC BY) license (http://creativecommons.org/licenses/by/4.0/). 